\title{
An Overview of Teaching Communication of Bad News in Medical School: Should a Lecture be Adequate to Address the Topic?
}

\section{Uma Visão Geral do Ensino de Comunicação de Más Notícias no Curso de Medicina: Será Uma Aula Teórica Adequada para Abordar o Tema?}

\author{
Filipe COUTINHO ${ }^{1}$, Anisha RAMESSUR ${ }^{2}$ \\ Acta Med Port 2016 Dec;29(12):826-831 - http://dx.doi.org/10.20344/amp.7909
}

\section{ABSTRACT}

Introduction: Delivering bad news is very common in medical daily practice. Several studies have shown a lack of effective communication skills amongst medical students, particularly concerning how to deliver bad news. The SPIKES protocol allows communicating bad news in a 6-step method. The aim of this study is to investigate the perspective of students related to this subject. Material and Methods: A 45 minute lecture "Breaking Bad News" was given to 160 students in the fifth and sixth years of the Medicine course, using the SPIKES' protocol training. After the lecture, an online survey was given to all students, and a cross-sectional and descriptive analysis of data extracted from survey was undertaken.

Results: Fifty-four students ( $21 \%$ of overall) answered the online survey. Eighty three percent said that theme should have an important role in their further daily medical practice, and most of students rated the physicians' role as challenging. Sixty percent of students expressed that communicating bad news was an integral part of the medical course curriculum. Regarding the SPIKES' protocol, $48 \%$ felt that the first step would be the easiest to put in practice, and $40 \%$ felt that the fifth step related to "Emotions" would be the most difficult.

Discussion: In general, the students would like to gain competencies in breaking bad news using a practical approach

Conclusions: Students highly valued theoretical and practical approaches in teaching of communication of bad news. Therefore, we encourage a combination approach in pre-graduate medical education.

Keywords: Clinical Competence; Communication; Education, Medical, Undergraduate; Portugal; Students, Medical; Truth Disclosure.

\section{RESUMO}

Introdução: A comunicação de más notícias é muito comum na prática médica diária. Vários estudos têm demonstrado um défice de competências por parte dos estudantes de medicina quanto à forma de dar más notícias. Com a aplicação do protocolo SPIKES torna-se possível adquirir treino de competências relacionadas com tal questão em seis etapas. O objetivo deste estudo é investigar a perspetiva dos estudantes sobre o problema.

Material e Métodos: Uma palestra de 45 minutos sobre "Comunicação de Más Notícias" visou os 160 estudantes do quinto e sexto ano de Medicina, usando o treino segundo protocolo de SPIKES. Após a palestra, foi implementado um inquérito online a todos os alunos, e foi realizada uma análise transversal e descritiva dos dados extraídos da pesquisa.

Resultados: Cinquenta e quatro alunos ( $21 \%$ do total) responderam ao questionário online. Oitenta e três por cento afirmaram que o tema deverá ter um papel importante na sua futura prática médica diária, e a maioria dos estudantes avaliou o papel dos médicos como desafiante. Sessenta por cento dos estudantes expressaram que comunicar más notícias fez parte integrante do currículo do curso de medicina. Em relação ao protocolo de SPIKES, 48\% sentiram que o primeiro passo seria o mais fácil de colocar em prática, e $40 \%$ sentiram que o quinto passo relacionado com as "Emoções" seria o mais difícil.

Discussão: Em geral, os alunos gostariam de se sentir capacitados para obter competências nas más notícias usando uma abordagem prática.

Conclusões: Os estudantes valorizam as abordagens teóricas e práticas no ensino da comunicação de más notícias. Deste modo, recomenda-se um modelo pedagógico combinado na educação médica pré-graduada.

Palavras-chave: Competência Clínica; Comunicação; Ensino Médico Pré-graduado; Estudantes de Medicina; Portugal; Revelação da Verdade.

\section{INTRODUCTION}

Delivering bad news is very common in the physician's daily practice, across all medical specialties and is being increasingly valued in training. Several studies have shown a lack of good quality teaching with regards to delivering bad news on the undergraduate medical course. ${ }^{1,2}$ Amongst junior doctors, it is observed that there are several factors that negatively influence their performance in communication of bad news such as a lack of communication competencies, ${ }^{3}$ own fear, lack support by their supervisors and time constraints. ${ }^{4}$

Nowadays, there is growing evidence that patients often want to know everything about their disease, ${ }^{5}$ increasing doctor's responsibility in delivering bad news in the right way to strengthen the patient-doctor relationship, and avoid litigation.

The method of delivering bad news to the patients

1. Medical Oncology Service. Centro Hospitalar do Porto. Porto. Portugal.

2. Medical Oncology Service. The Royal Marsden Hospital. London. United Kingdom.

$\bowtie$ Autor correspondente: Filipe Coutinho. filipecoutinho184@hotmail.com

Recebido: 09 de junho de 2016 - Aceite: 23 de setembro de 2016 | Copyright @ Ordem dos Médicos 2016 
significantly influences their satisfaction with medical care, level of understanding of disease and emotional state. As a result to this, Robert Buckman created a six-point protocol, known by the acronym SPIKES, that allows communicating bad news in a step by step sequence. One of main goals of this model is to give attention and emphasis to the message being transmitted, as well to help to take off responsibility to the messenger that delivers the bad news. ${ }^{6}$ Due to its positive effect on patient outcomes, the protocol is included in the guidelines of clinical communication. ${ }^{7}$ Each step comprises a list of patterns and behaviors to deliver bad news in an organized manner, and the interview should begin with "Setting" ( $1^{\text {st }}$ step), followed by "Perception" $\left(2^{\text {nd }}\right.$ step) and "Invitation" ( $3^{\text {rd }}$ step) which primarily focuses on finding out "how much the patient knows" and "how much he want to know" about disease, respectively. The fourth step is associated with providing information to the patient and is named as "Knowledge". The "Emotion and Empathy" step ( $5^{\text {th }}$ step) refers to patients' emotions and how doctor should respond to them. Finally, in the last step ("Strategy and Summary") the doctor should provide a summary to patients as well as discussing a good plan.,

In a recent German study, it was observed that only $46.2 \%$ of cancer patients were completely satisfied regarding the way in which bad news were delivered to them. ${ }^{8}$

Due to the evidence of poor communication in breaking bad new amongst medical professionals, several strategies were developed to educate them on how to deliver bad news effectively, ranging from a theoretical manner to a practical approach, and a combination of both. ${ }^{9}$ Despite the advantages and disadvantages for each approach, it was perceived that they could improve communication skills.

The reality of the Portuguese medical education is not different from other medical schools regarding in the limited teaching of communicating bad news. This could be due to a standardized theoretical and technician teachingapproach, the increasing number of medical students, and the limited time to implement a consistent program in a practical model.

In the Albuquerque study ${ }^{10}$ which included 1087 medical students from all Portuguese medical schools, it was found that $25 \%$ of them have never been in a situation of communicating bad news, and only less than $20 \%$ felt prepared to act in a situation of delivering bad news.

Nevertheless, some efforts have been made in order to improve the lack of medical communication in the medical school curriculum, with implementation of a postgraduate program, and the outcomes achieved were good. ${ }^{11}$ To reinforce this data, a study involving Portuguese medical students has shown that most of them had felt that improving their medical communication skills with patients had a significant impact on their future medical practice. It was also noticed that they showed poor knowledge on how to communicate bad news. ${ }^{12}$

This study allows us to assess the baseline knowledge of medical students regarding how to address a patient with
"Communication of Bad News", as well as their perspective concerning a lecture as a main vehicle to learn this topic. With respect to data analysis, we reveal some interesting conclusions which can improve understanding in this field, as well as to improve better outcomes in medical communication within undergraduate education.

\section{MATERIAL AND METHODS \\ Study design}

This study consisted initially of a forty-five minutes lecture in the main auditorium of Faculty of Health Sciences of University of Beira Interior, in Covilhã (Portugal), on 19 ${ }^{\text {th }}$ December 2013. The lecture aimed to provide a theoretical basis on "How to break bad news" taking in account the literature evidence and SPIKES protocol. The participating students were in the last 2 years of their Master Degree of Medicine ( $5^{\text {th }}$ and $6^{\text {th }}$ grade). One of the authors (FC) was the invited by Faculty of Health Sciences to perform the seminar. As a medical oncology physician, he incorporated the application of the SPIKES protocol into his regular clinical practice to help with delicate delivery of bad news to his patients.

An online questionnaire was created using Google Docs $^{\mathrm{TM}}$ by Microsoft Office $2013^{\mathrm{TM}}$, which it was applied and freely accessible to all attendees. It consisted mainly in Likert-type questions, and few open questions. The questionnaire was open for one month (April 2014) in which time the students had full access. All questions in the questionnaire had to be answered to complete the survey. All answers were subjected to anonymity and confidentiality. The inclusion criteria for the $5^{\text {th }}$ and $6^{\text {th }}$ year medical students from University of Beira Interior included presence at the lecture and the need to have completed the whole questionnaire.

\section{Participants}

All $5^{\text {th }}$ and $6^{\text {th }}$ year medical students, precisely 260 students (120 related to $5^{\text {th }}$ year and 140 linked to $6^{\text {th }}$ year) from the Health Sciences Faculty of University of Beira Interior that attended the lecture were invited to participate in online questionnaire.

\section{Statistical analysis}

This study comprised a cross-sectional and descriptive (frequencies and percentages) analysis of data, using Excel $^{\mathrm{TM}}$ basic statistics.

\section{RESULTS}

Fifty-four students attended and completed the online survey, representing $21 \%$ of the total number of students.

It was noticed that $38(70 \%)$ students had heard about how to break bad news in some period of their undergraduate medical training, mainly during Medical Oncology or Health Psychology classes. Participants who had previously dealt with a situation of delivering bad news, 15 (28\%) students answered affirmatively, and in their performance selfassessment, $60 \%$ believed that it had been reasonable and 
$33 \%$ that had been good.

Taking in account previous training in communication of bad news, 28 (52\%) students never had a formal training, $24(44 \%)$ students only have had theoretical training and 2 $(4 \%)$ students received both types of training.

In order to understand students' perception regarding the role of breaking bad news in medical daily practice, they were faced with some questions. Most of them (92\%) felt that including it in the medical undergraduate curriculum was highly relevant to clinical training. A high proportion $(83 \%)$ of students has admitted that delivering bad news performs an essential role in daily medical practice. According to clinician's difficulty in delivering bad news, $57 \%$ of students assumed that physicians have a difficult task, and $33 \%$ thought that is very challenging. According to their perspective regarding to the fears by physician in the situation of delivering bad news, there was a heterogeneity in their answers: fear about emotional reaction from patient/ relatives (26\%), afraid of withdraw hope to patient $(26 \%)$, not to be not capable to express his ideas/knowledge in a good manner $(7 \%)$, or afraid of being guilty for the situation $(8 \%)$. The results show that $18(33 \%)$ students had chosen all this options.

For a good progress in the process of delivering bad news, $21(39 \%)$ students found that the physician needs to create an empathic relationship, having capacity for proper management of emotions between doctor and patient $(30 \%)$ or having ability to properly answer all questions asked by the patient $(20 \%)$.

In a theoretical reflection more than a half $(57 \%)$ of students felt that the more difficult task to do in clinical practice was to discuss the end of a curative treatment and switch to palliative management (Fig. 1).

Concerning their evaluation of lecture as a learningbased program, $45(83 \%)$ students were pleased to have the presentation in a main auditorium, and 20 students of them have expressed themselves very satisfied with respect to the schedule time to do the presentation. On assessment of instructor's performance, $52(96 \%)$ students were convinced of his good conceptual knowledge and 44 $(82 \%)$ highlighted his capacity to focus the main points of interest. According to appraisal in efficacy to provide good examples of clinical practice by lecturer, $17(32 \%)$ students seemed to feel somewhat satisfied, $5(9 \%)$ felt unhappy and $2(4 \%)$ found to be very unhappy. In respect to the proficiency of lecture to catch their continuous attention during the seminar, $22 \%$ and $13 \%$ showed poor satisfaction or unsatisfied, respectively.

Regarding the SPIKES protocol, ninety-six percent of students said that learning the protocol could be beneficial to their clinical practice in future, independently of which speciality they would want to choose.

After the explanation of all steps of SPIKES' protocol, it was important to understand which step they felt would be easier to perform in a clinical practice context. In a hypothetical way, $50 \%$ of students had the opinion that the first step could be the easiest; on the other hand, they thought that the most difficult steps could be the fourth and fifth steps, concerning the "Knowledge" and "Emotions", respectively (Fig. 2).

One of the main results was that most of the students were convinced that solely a lecture may not be an effective teaching method for communication of bad news. In Fig. 3 , it is noticed that they have selected several preferences towards to a theoretical-practical educational program.

Their interest in learning more about Medical Communication was evident (Fig. 4), and it was remarkable that $64 \%$ of students would like to learn all themes proposed in another seminar.

\section{Which of the following topics do you considered the most difficult to deal in clinical practice?}

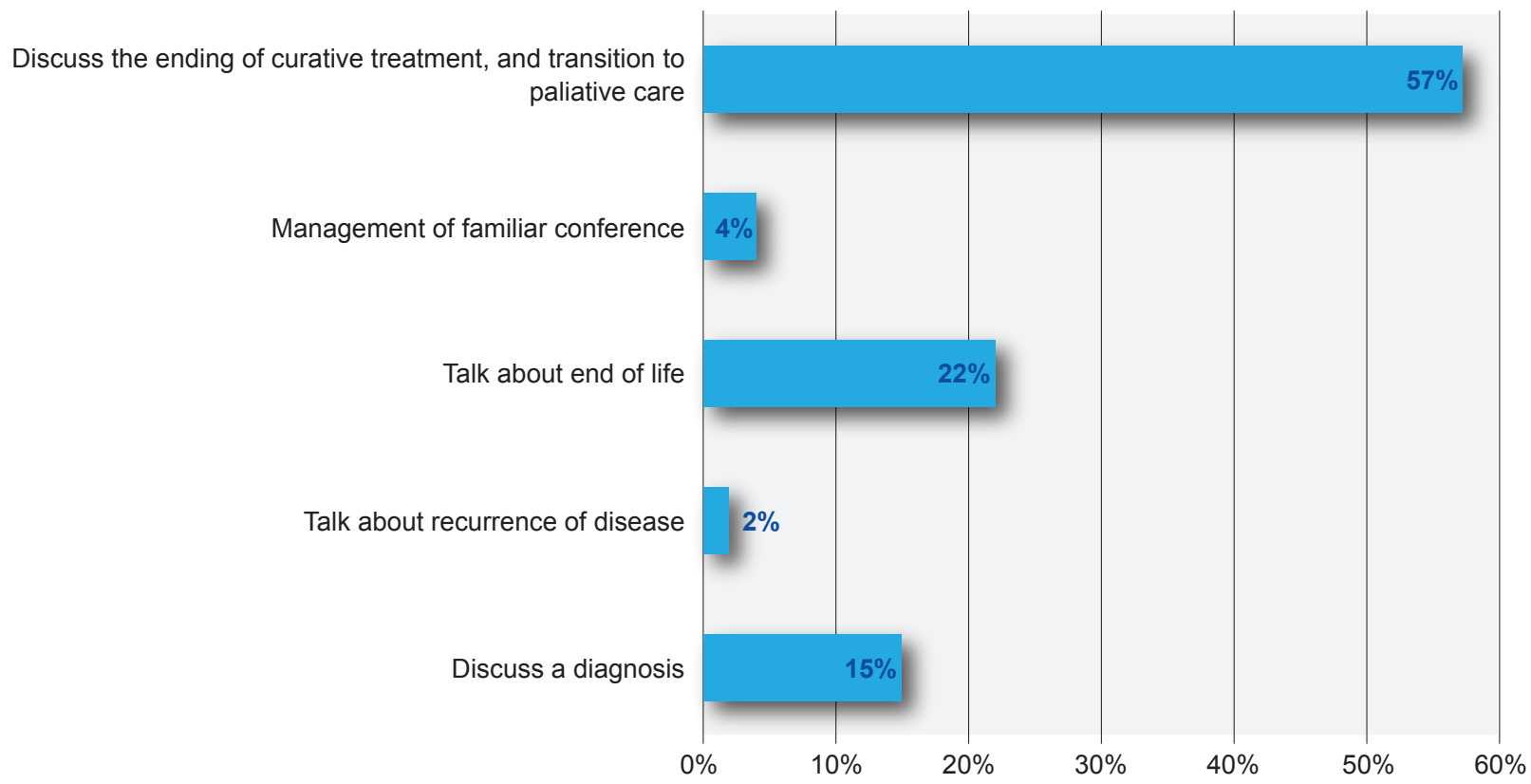

Figure 1 - Students' judgment regarding the most difficult topics to discuss in clinical practice 
Regarding the SPIKES' protocol, which step do you consider the most easier or harder to preform in practice?

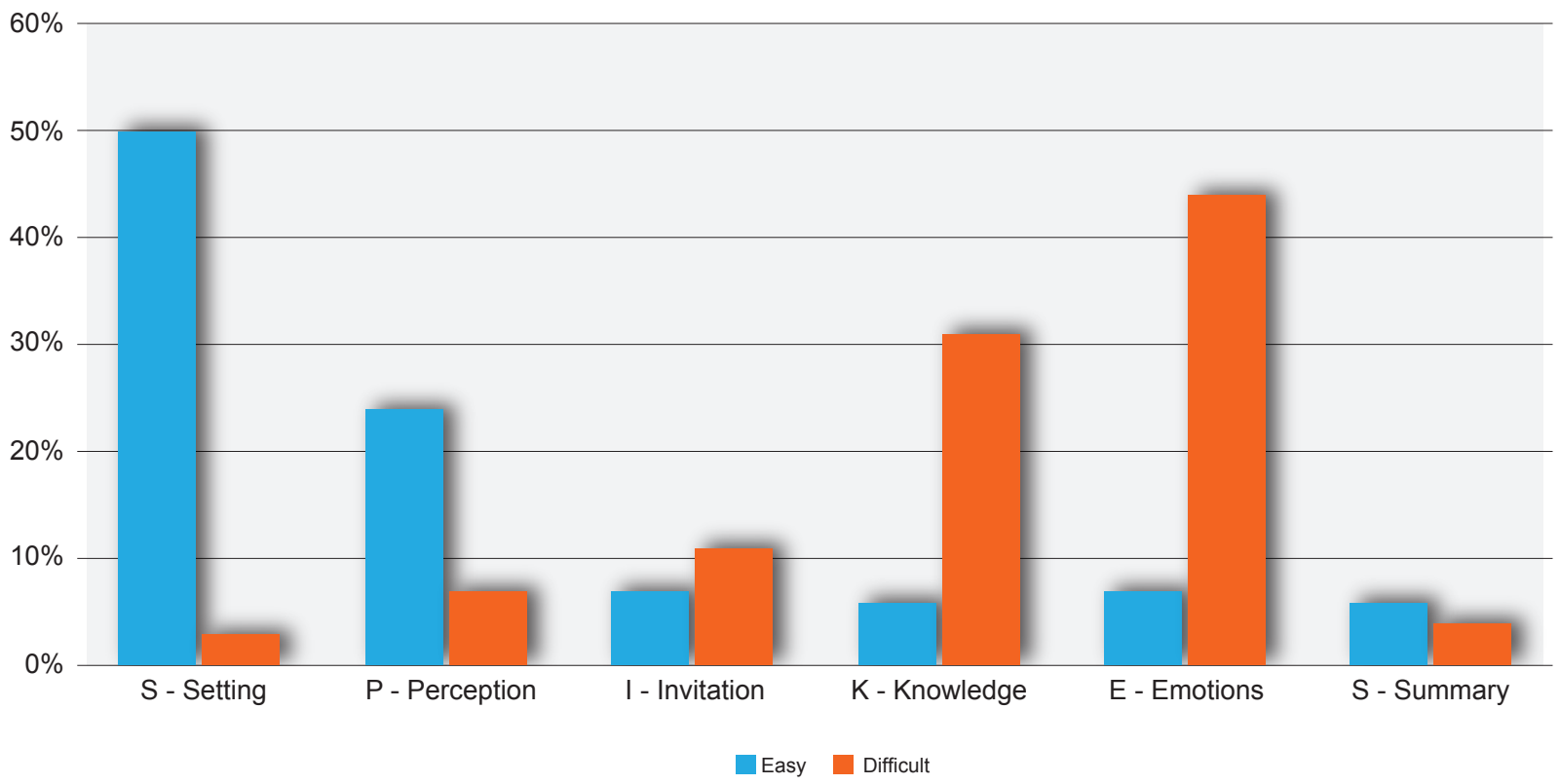

Figure 2 - Opinion of students regarding the level of difficulty of SPIKES protocol steps

In your opinion, what is the best way to learn how to communicate bad news?

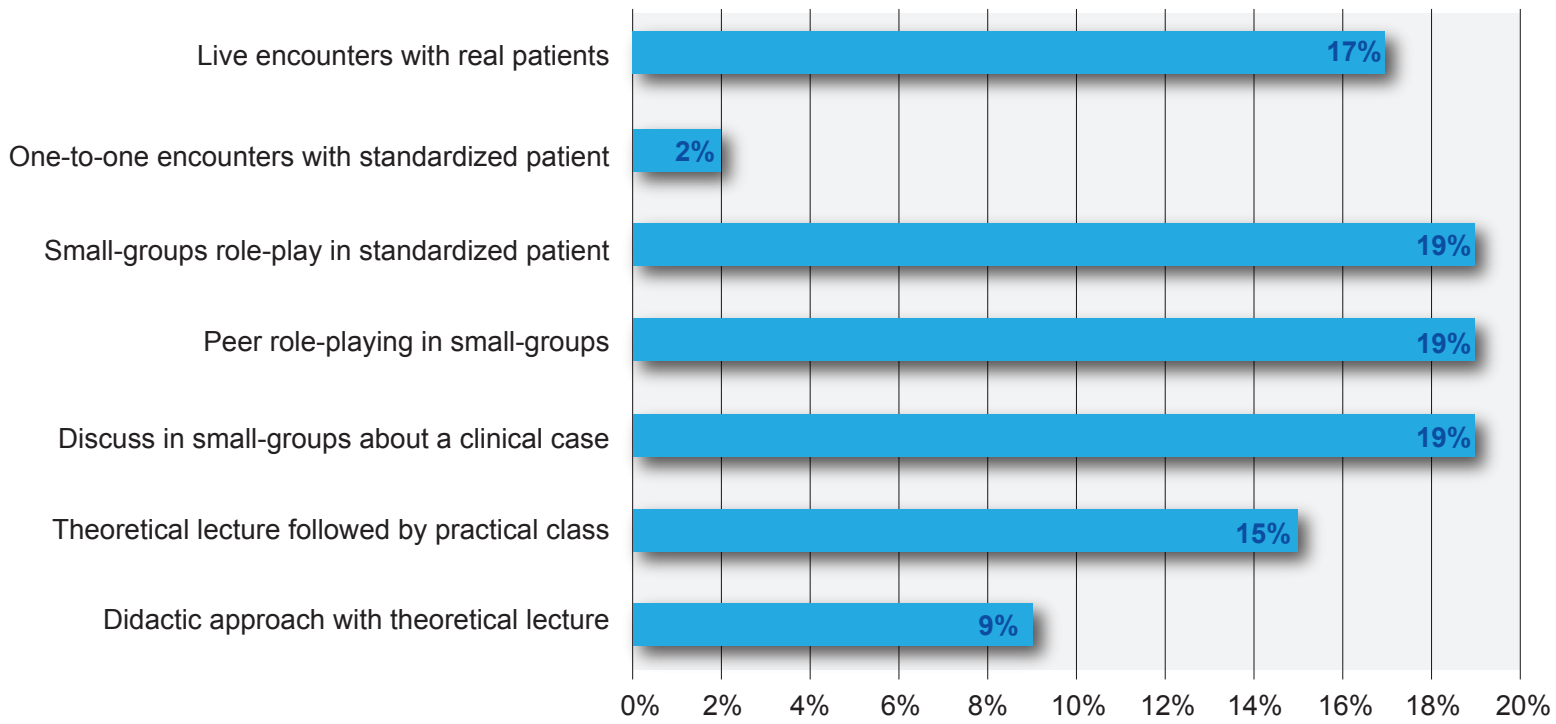

Figure 3 - Students perspective regarding the best way to learn communication of bad news

\section{DISCUSSION}

Training in Communication is very important to physicians' clinical practice as it provides a best care to patient and strengthens relationship and therapeutic alliance between clinicians and patients. Additionally, it is also associated with less stress and risk of burnout on health professionals. ${ }^{13,14}$ It is important that acquisition of skills in clinical communication needs to be started in undergraduate medical teaching, ${ }^{15,16}$ and should be a prerequisite to basic knowledge of a future doctor, independently of specialty chosen. In a study conducted by Epner \& Baile, ${ }^{17}$ which consisted in learning on how to face a difficult conversation, most of medical trainees had agreed that it was a great value according to their future clinical practice. Others studies demonstrated that acquisition of communication skills are very welcome in medical field. ${ }^{18}$

In the current study, most students highly agreed that training in Communication of Bad News should be integrated in their medical curriculum, and useful in future for their medical practice. Surprisingly, the Angus et al study displayed that regarding admission criteria for freshman internal medicine residents, only half of directors classified the acquisition of skills in communication of bad news as high priority. Additionally, they did not consider the 
Which topic you wish to discuss at a future lecture?

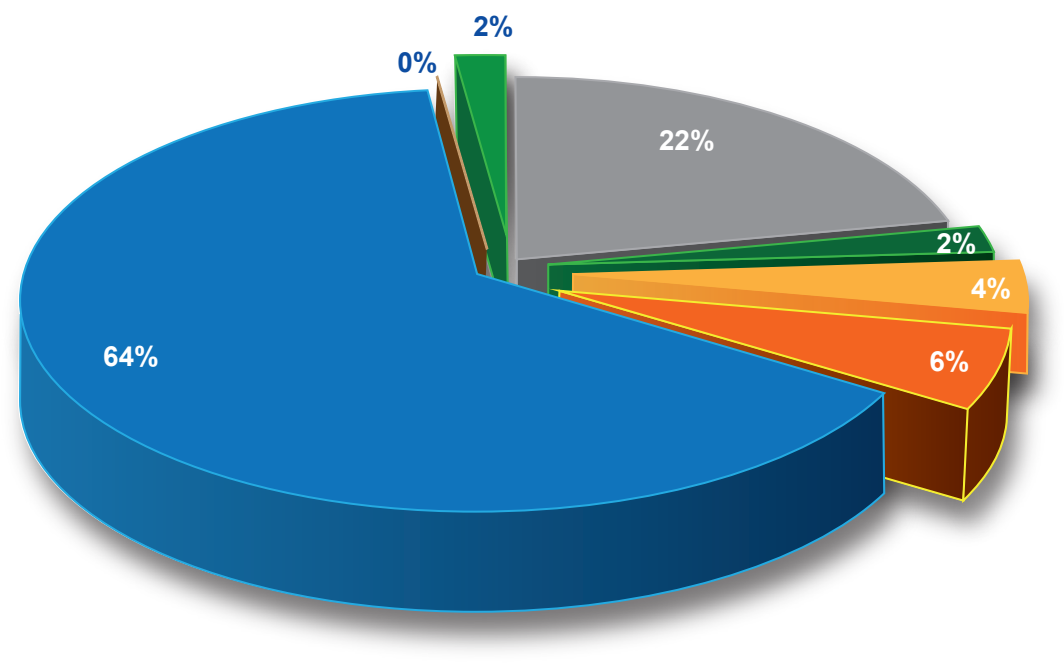

Transition from curative to paliative treatment

Discuss treatment options and informed consent

Talk about sexuality and infertility in oncology

How to prepare a familiar conference

All the options above

None

Other

Figure 4 - Other subjects to discuss in a future lecture

communication skills as an important prerequisite for the trainee. ${ }^{19}$

This contrasts with students' overall perception, since Albuquerque's study found that majority of students (95\%) have agreed that it should be important to learn non-technical skills (such as communication skills) in medical curricula. ${ }^{10}$ The health professionals' disbelief in respect of efficacy of training communication skills in clinical practice is one barrier that has to be overcome. ${ }^{20}$ Even in the presence of an insufficient high quality data in assessment of its impact on clinical outcomes, there is a tendency towards its benefit in health professionals, showing a reduction on emotional distress, ${ }^{21}$ moderate improvement in self-reported ratings on communication skills, ${ }^{22}$ and improvement of communication skills. ${ }^{23}$

The students who faced a breaking bad news situation in the past had classified their performance in delivering bad news from reasonable to good. Maybe the explanations for their scoring was that $70 \%$ had had a previous approach to the theme and $48 \%(n=26)$ had formal training in the past. Both reasons could allow them to a better knowledge in this field, as literature shows that previous training brings benefits in improving their skills and confidence. ${ }^{18,24}$

According to clinical relevance of SPIKES' protocol, the students thought it would be useful to better communicate bad news; cancer patients share this opinion as they seemed to be happy for the application of breaking bad news guidelines in a clinical context. ${ }^{25}$

It was no surprise that the students reported that the lecture failed to capture their full-time attention. When they were questioned about which type of education program would prefer to have in future, it was obvious that, in opposition to the current teaching model, they would like to have a program on theoretical-practical basis centered in small groups. This is in agreement with scientific evidence once it has been shown that this strategy allows to share experiences with colleagues, stimulates team work and open discussion of problems, strengthens the confidence in skills, and provides a supporting environment. ${ }^{18,26,27}$ Another study found that a role-play strategy can be easily implemented in preclinical stage, based on an effective methodology with no additional costs. ${ }^{28}$ To support these opinion, it seems that a solely didactic approach is not effective to transmit a clear information, change the physician performance or either to stimulate a continuously attention. ${ }^{29}$

It was no surprise that half of students had selected the first step of SPIKES protocol as what they think that could be the easiest to implement in a practical context, contrasting with the last two steps, which they seemed to think as the most difficult to do. These ideas are in concordance with reality, as Baile et a/ $\left.\right|^{5}$ have shown in their survey that included 500 delegates at 1998 Annual Meeting of the American Society of Clinical Oncology (ASCO), once $30.1 \%$ stated that the "Setting" step was the easiest, and $52.4 \%$ that "Empathy" step was that the most difficult.

Some limitations of this study need to be raised: first, the fact that the questionnaire was optional could have limited the number completed, as suggested by the relatively small dataset obtained; secondly, by using cross-sectional data it only revealed the opinion of students at a particular point in time and consequently does not take into account if their perception changed along the course of medical school. It would be interesting to assess their point of view in different stages of the medical graduation (eg. pre-clinical versus clinical rotations); thirdly, this study only assessed the perception of students based on a didactic approach, not allowing to assess if their feelings changed if exposed to a practical or mixed (theoretical-practical) model. The Rosenbaum et al review showed that there could be differences on outcomes depending on educational model implemented. ${ }^{9}$

From the authors' point of view, this study can stimulate further research in this field in order to provide better knowledge of best educational strategies to improve 
learning communication of bad news.

\section{CONCLUSIONS}

This study illustrates that students need to acquire more knowledge about how to communicate bad news.

The data helped to give a greater insight into understanding more about the students' needs and concerns, and suggested ways of improving undergraduate teaching on Communication of Bad News.

The results from this study support that students prefer a combination learning model, which conveys a theoretical exposure with a chance for them to put in practice what they have learned.

This study raises the importance of implementing a more effective teaching model for the Communication of Bad News into the medical school curriculum.

\section{ACKNOWLEDGEMENTS}

The authors thank all students who participated in this investigation, and Faculty of Health Sciences of University

\section{REFERENCES}

1. Fallowfield $L$, Jenkins V. Communicating sad, bad, and difficult news in medicine. Lancet. 2004;363:312-9.

2. Barnett MM, Fisher JD, Cooke H, James PR, Dale J. Breaking bad news: consultants' experience, previous education and views on educational format and timing. Med Educ. 2007;41:947-56.

3. Eggly S, Afonso N, Rojas G, Baker M, Cardozo L, Robertson RS. An assessment of residents' competence in the delivery of bad news to patients. Acad Med. 1997;72:397-9.

4. Dosanjh S, Barnes J, Bhandari M. Barriers to breaking bad news among medical and surgical residents. Med Educ. 2001;35:197-205.

5. Baile WF, Buckman R, Lenzi R, Glober G, Beale EA, Kudelka AP. SPIKES - a six-step protocol for delivering bad news: application to the patient with cancer. Oncologist. 2000;5:302-11.

6. Buckman R. Breaking bad news: a six-step protocol. In: Buckman R, editor. How to break bad news. A guide for health care professionals. Baltimore: Johns Hopkins University Press; 1992. p. 65-97.

7. EPEC - Education for Physicians on End of Life Care. Participant's Handbook: Module 2: Communicating Bad News EPEC Project. New York: Robert Wood Johnson Foundation; 1999.

8. Seifart C, Hofmann M, Bär T, Riera KJ, Seifart U, Rief W. Breaking bad news-what patients want and what they get: evaluating the SPIKES protocol in Germany. Ann Oncol. 2014;25:707-11.

9. Rosenbaum ME, Ferguson KJ, Lobas JG. Teaching medical students and residents skills for delivering bad news: a review of strategies. Acad Med. 2004;79:107-17

10. Albuquerque NF. Comunicação de más notícias a pacientes: Conhecimento, experiência, dificuldades e padrões de comportamento de alunos de medicina. Covilhã: Universidade da Beira Interior; 2013.

11. Carvalho IP, Pais VG, Almeida SS, Ribeiro-Silva R, Figueiredo-Braga $M$, Teles A, et al. Learning clinical communication skills: outcomes of a program for professional practitioners. Patient Educ Couns. 2011;84:849.

12. Leite RA. Competências essenciais de comunicação clínica no curso de medicina da UBI: avaliação e revisão curricular. Covilhã: Universidade da Beira Interior; 2013.

13. Ramirez AJ, Graham J, Richards MA, Cull A, Gregory WM, Leaning MS, et al. Burnout and psychiatric disorder among cancer clinicians. $\mathrm{Br} J$ Cancer. 1995;71:1263-9.

14. Graham J, Potts HW, Ramirez AJ. Stress and burnout in doctors. Lancet. 2002;360:1975-6.

15. Simpson M, Buckman R, Stewart M, Maguire P, Lipkin M, Novack D, et al. Doctor-patient communication: the Toronto consensus statement. BMJ. 1991;303:1385-7.

16. Association of American Medical Colleges. Report 3: Contemporary Issues of Medicine: Communication in Medicine. Washington: AAMC; of Beira Interior for the opportunity to perform the medical seminar and survey.

\section{PROTECTION OF HUMANS AND ANIMALS}

The authors declare that the procedures were followed according to the regulations established by the Clinical Research and Ethics Committee and to the Helsinki Declaration of the World Medical Association.

\section{DATA CONFIDENTIALITY}

The authors declare having followed the protocols in use at their working center regarding patient's data publication.

\section{CONFLICTS OF INTEREST}

The authors declare that there are no conflicts of interest.

\section{FUNDING SOURCES}

No subsidies or grants contributed to this work.

1999.

17. Epner DE, Baile WF. Difficult conversations: teaching medical oncology trainees communication skills one hour at a time. Acad Med. 2014;89:578-84.

18. Baile WF, Kudelka AP, Beale EA, Glober GA, Myers EG, Greisinger AJ, et al. Communication skills training in oncology. Description and preliminary outcomes of workshops on breaking bad news and managing patient reactions to illness. Cancer. 1999;86:887-97.

19. Angus S, Vu TR, Halvorsen AJ, Aiyer M, McKown K, Chmielewski AF, et al. What skills should new internal medicine interns have in july? A national survey of internal medicine residency program directors. Acad Med. 2014;89:432-5

20. Razavi D, Delvaux N. Communication skills and psychological training in oncology. Eur J Cancer. 1997;33:S15-21.

21. Roter DL, Hall JA, Kern DE, Barker LR, Cole KA, Roca RP. Improving physicians' interviewing skills and reducing patients' emotional distress. A randomized clinical trial. Arch Intern Med. 1995;155:1877-84.

22. Brown JB, Boles M, Mullooly JP, Levinson W. Effect of clinician communication skills training on patient satisfaction. A randomized, controlled trial. Ann Intern Med. 1999;131:822-9.

23. Moore PM, Rivera Mercado S, Grez Artigues M, Lawrie TA. Communication skills training for healthcare professionals working with people who have cancer. Cochrane Database Syst Rev. 2013;3:CD003751.

24. McElligott F, Nicholson A, Molloy EJ. The perception and impact of a "breaking bad news" module on paedriatic medical students. Arch Dis Child. 2012;97:290-1.

25. Schofield PE, Beeney LJ, Thompson JF, Butow PN, Tattersall MH, Dunn SM. Hearing the bad news of a cancer diagnosis: the Australian melanoma patient's perspective. Ann Oncol. 2001;12:365-71.

26. Gibon AS, Merckaert I, Liénard A, Libert Y, Delvaux N, Marchal S, et al. Is it possible to improve radiotherapy team members' communication skills? A randomized study assessing the efficacy of a 38-h communication skills training program. Radiother Oncol. 2013;109:170-7.

27. Fallowfield L, Jenkins V, Farewell V, Solis-Trapala I. Enduring impact of communication skills training: results of a 12-month follow-up. $\mathrm{Br} \mathrm{J}$ Cancer. 2003;89:1445-9.

28. Luttenberger K, Graessel E, Simon C, Donath C. From board to bedside - training the communication competences of medical students with role plays. BMC Med Educ. 2014;14:135.

29. Davis D, O'Brien MA, Freemantle N, Wolf FM, Mazmanian P, TaylorVaisey A. Impact of formal continuing medical education: do conferences, workshops, rounds, and other traditional continuing education activities change physician behavior or health care outcomes? JAMA 1999;282:867-74. 